\title{
Clinicopathological Features and Prognostic Implication of Gastric Carcinoma with Lymphoid Stroma
}

\author{
Jung-Soo Pyo $\mathbb{D}^{1},{ }^{1}$ Nae Yu Kim $\mathbb{D}^{\circ},{ }^{2}$ Byoung Kwan Son $\mathbb{D},{ }^{3}$ Hyo Young Lee $\mathbb{D},{ }^{3}$ Il Hwan Oh $\mathbb{D},{ }^{3}$ \\ and Kwang Hyun Chung $\mathbb{D}^{3}$ \\ ${ }^{1}$ Department of Pathology, Daejeon Eulji University Hospital, Eulji University School of Medicine, Daejeon, Republic of Korea \\ ${ }^{2}$ Department of Internal Medicine, Daejeon Eulji University Hospital, Eulji University School of Medicine, Daejeon, Republic of Korea \\ ${ }^{3}$ Department of Internal Medicine, Nowon Eulji University Hospital, Eulji University School of Medicine, Seoul, Republic of Korea
}

Correspondence should be addressed to Byoung Kwan Son; sbk1026@eulji.ac.kr

Received 6 October 2020; Revised 4 November 2020; Accepted 15 November 2020; Published 3 December 2020

Academic Editor: Bruno Annibale

Copyright ( 2020 Jung-Soo Pyo et al. This is an open access article distributed under the Creative Commons Attribution License, which permits unrestricted use, distribution, and reproduction in any medium, provided the original work is properly cited.

\begin{abstract}
Background/Objective. Gastric carcinoma with lymphoid stroma (GCLS) has been referred to as lymphoepithelioma-like carcinoma and medullary carcinoma. The present study aims at elucidating the clinicopathologic features and prognostic implications of GCLS through a meta-analysis. Methods. This study included 34 eligible studies and 1757 GCLSs. The clinicopathologic characteristics of GCLS were investigated from eligible studies, and the meta-analysis was performed. In addition, we compared the survival rates between GCLS and non-GCLS. Results. The estimated rate of GCLS was 0.062 (95\% confidence interval (CI) 0.040-0.097). GCLS was significantly correlated with the diffuse type of Lauren's classification, proximal tumor location, lessfrequent lymphatic invasion, and lower pTNM stage. However, there was no significant difference in age, sex, tumor differentiation, vascular invasion, perineural invasion, pT stage, lymph node metastasis, and distant metastasis between GCLS and non-GCLS patients. EBV positive rates in GCLS and non-GCLS patients were 0.723 (95\% CI 0.643-0.791) and 0.064 (95\% CI 0.039-0.103), respectively. HER2 expression in GCLS was significantly lower than that in non-GCLS. GCLS patients had a more favorable prognosis than that of non-GCLS patients (hazard ratio 0.500, 95\% CI 0.305-0.821). Conclusion. GCLS comprised $6.2 \%$ of overall GC and more frequent in the proximal portion of the stomach. Since GCLS was associated with better prognosis, the histologic finding can be useful for predicting the patient's prognosis.
\end{abstract}

\section{Introduction}

Gastric carcinoma (GC) includes various subtypes, such as tubular adenocarcinoma, poorly cohesive carcinoma, and GC with lymphoid stroma (GCLS) [1]. Among these subtypes, GCLS accounts for 1-7\% of overall GC [1]. According to the WHO classification, medullary and lymphoepithelioma-like carcinomas are synonyms for GCLS [1]. In GCLS, tumor cells have irregular sheets, trabeculae, ill-defined tubules, or syncytial pattern [1]. In addition, the characteristic histology is a prominent lymphocytic infiltrate with intraepithelial lymphocytes [2-35]. Although GCLS usually has a well-defined tumor border, small clusters within prominent intratumoral lymphocytes can have infiltrative borders [36]. GCLS is known to correlate with the male sex, proximal tumor location, and Epstein-Barr virus (EBV) positivity. However, some clinicopathologic features of GCLS vary [2-35]. In addition, histologic features of GCLS, which has a low prevalence, may overlap with that of poorly differentiated adenocarcinoma. These factors can affect variable clinicopathologic features between reports. EBV positivity was frequently found in GCLS. However, detailed clinicopathologic features with respect to EBV positivity are unclear. We investigated the prevalence of GCLS in overall GC through a meta-analysis. In addition, the clinicopathologic features and prognosis between GCLS and non-GCLS were compared. In addition, subgroup analysis based on EBV positivity was performed in predicting the prognosis of GCLS. 


\section{Materials and Methods}

2.1. Published Study Search and Selection Criteria. Relevant articles were obtained by searching the PubMed database through April 30, 2020. We used the following keywords: "stomach or gastric" and "gastric carcinoma with lymphoid stroma or medullary carcinoma or lymphoepithelioma-like carcinoma." The titles and abstracts of all searched articles were screened for inclusion and exclusion. Included articles should have information on clinicopathological characteristics or prognosis in GCLS. However, nonoriginal articles, such as case reports and review articles, were excluded. In addition, those not written in English were not included in the present study. This protocol was reviewed and approved by the Institutional Review Board of Eulji University Hospital (EMC 2020-09-007).

2.2. Data Extraction. Data extracted from 34 eligible studies [2-35] included the author's information, study location, number of patients analyzed, the prevalence and the clinicopathological characteristics of GCLS, the correlation with various markers, and overall survival rates of GCLS. For the quantitative aggregation of the survival results, the correlation between GCLS and survival was analyzed according to the hazard ratio (HR) using one of three methods. In studies that did not record the HRs or confidence intervals (CIs), we calculated these variables from the data using the HR point estimate, the log-rank statistic or its $P$ value, and the $\mathrm{O}-\mathrm{E}$ statistic (the difference between the number of observed and expected events) or its variance. If these data were unavailable, the HR was estimated using the total number of events, number of patients at risk in each group, and the log-rank statistic or its $P$ value. Finally, if the only useful data were in the form of graphical representations of survival distributions, survival rates were extracted at specified times to reconstruct the $\mathrm{HR}$ estimate and its variance under the assumption that patients were censored at a constant rate during the time intervals [37]. The published survival curves were read independently by two authors in order to reduce variability. The HRs were then combined using Peto's method [38]. Data associated with survival were extracted after a 60-month follow-up period. All data were obtained by two independent authors.

2.3. Statistical Analyses. The meta-analysis was performed using the Comprehensive Meta-Analysis software package (Biostat, Englewood, NJ, USA). The prevalence of GCLSs among GC was investigated. Subgroup analyses based on the depth of the tumor, was performed. The clinicopathological characteristics of GCLS, such as age, sex, size, tumor differentiation, lymphovascular invasion, and pTNM stages, were compared with those of non-GCLS. EBV positivity from EBER in situ hybridization between GCLS and nonGCLS was compared. In addition, the differences of PD-L1, HER2, and p53 immunohistochemical expressions between GCLS and non-GCLS were investigated. Heterogeneity between the studies was checked by the $Q$ and $I^{2}$ statistics and expressed as $P$ values. Additionally, sensitivity analysis was conducted to assess the heterogeneity of eligible studies and the impact of each study on the combined effects. Eligible studies included various populations having different tumor subtypes, tumor stages, and treatments. In addition, although the molecular and immunohistochemical tests were qualified, the methods were different between laboratories. Thus, in interpretations for estimated results, a random-effect model rather than a fixed-effect model was used. To assess publication bias, Begg's funnel plot and Egger's test were used; if it was significant, the fail-safe $N$ and trim-fill tests were additionally used to confirm the degree of publication bias. The results were considered statistically significant at $P<0.05$

\section{Results}

3.1. Selection and Characteristics of the Studies. From the primary search using the PubMed database, we found 316 relevant articles. In screening and reviewing, we excluded 117 because they were not original. Sixty-six articles had no information or insufficient information for a meta-analysis. Among the remaining articles, 489 reports were excluded for the following reasons: articles reporting other diseases $(n=75)$, nonhuman studies $(n=17)$, and a language other than English $(n=7)$ (Figure 1). Finally, 34 eligible articles were included in the meta-analysis (Table 1). These studies included 1757 GCLS and 14,926 non-GCLS patients.

3.2. Prevalence of GCLSs. The estimated prevalence rate of GCLS among GCs was 0.062 (95\% CI $0.040-0.097$ ) (Table 2). In early GC (EGC) and advanced GC (AGC), GCLSs made up 0.054 (95\% CI 0.022-0.129) and 0.136 (95\% CI 0.119-0.155), respectively. There was no significant difference in the prevalence of GCLS between EGC and AGC ( $P=0.392$ in a metaregression test). In addition, in sensitivity tests, there was no significant impact of each study on estimated prevalence rate.

\subsection{Comparisons of Clinicopathological Characteristics} between GCLS and Non-GCLSs. Next, we compared the clinicopathological characteristics between GCLS and nonGCLS patients. Statistical significances was found in the tumor size, Lauren's classification, tumor location, lymphatic invasion, and pTNM stage using the metaregression tests (Table 3). The tumor sizes were $3.275 \mathrm{~cm}$ (95\% CI 2.521$4.029 \mathrm{~cm})$ and $4.636 \mathrm{~cm}(95 \%$ CI $3.786-5.486 \mathrm{~cm})$, respectively. GCLSs were frequently found in the diffuse type of Lauren's classification. Tumors occurring in the proximal $1 / 3$ of the stomach comprised $24.9 \%$ and $14.8 \%$ of GCLS and non-GCLS, respectively. The lymphatic invasion was less frequent in GCLS than in non-GCLS. Stage I and II GCs occurred in 0.750 (95\% CI $0.599-0.858)$ and 0.500 (95\% CI 0.317-0.683) of GCLS and non-GCLS, respectively. However, there were no significant differences in the age, sex, tumor differentiation, vascular invasion, perineural invasion, $\mathrm{pT}$ stage, and lymph node metastasis.

EBV positivity was found in $72.3 \%$ of GCLSs and $6.4 \%$ of non-GCLSs, respectively (Table 4). There was a significant difference in EBV positivity between GCLSs and nonGCLSs $(P<0.001$ in the metaregression test). Microsatellite 


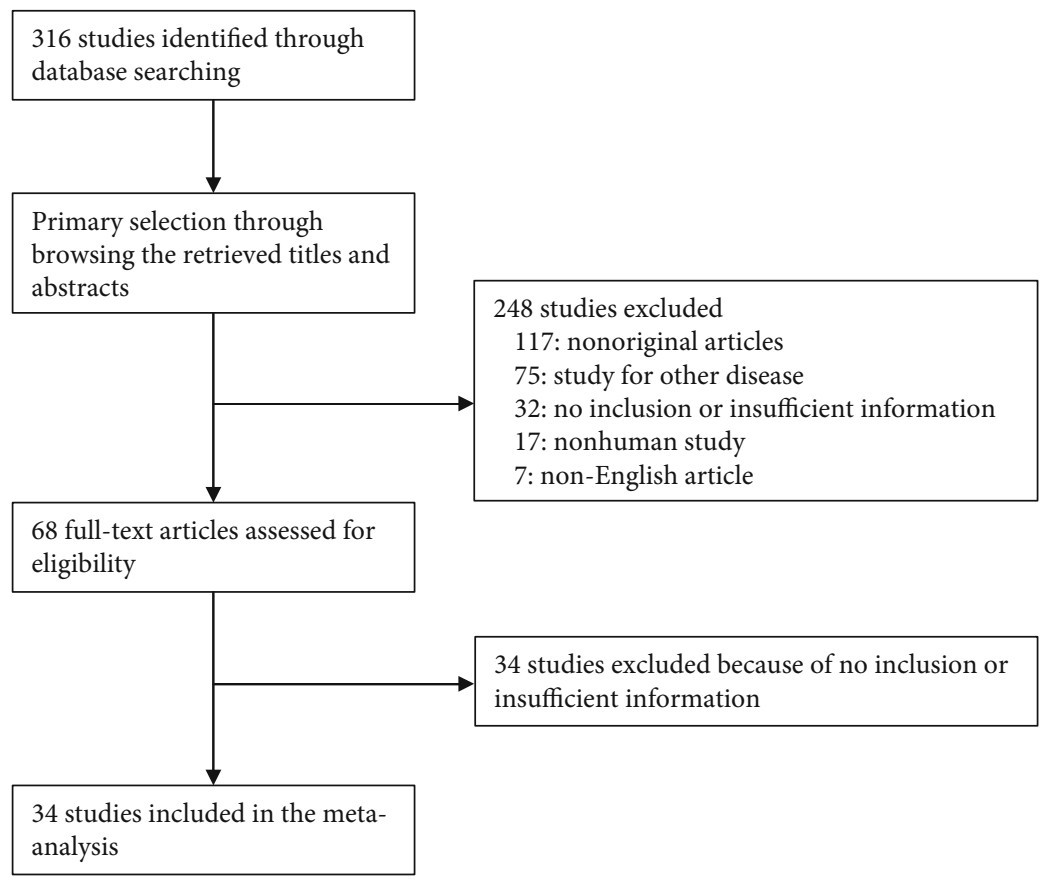

FIGURE 1: Flow chart of study search and selection methods.

instability was found in $5.9 \%$ of GCLSs. PD-L1 immunohistochemical expression rates in GCLS occurred in 0.677 (95\% CI 0.497-0.817) and 0.742 (95\% CI 0.563-0.865) in tumor and immune cells, respectively. HER2 immunohistochemical expression rates were 0.026 (95\% CI 0.005-0.120) and 0.632 (95\% CI 0.403-0.813) in GCLS and non-GCLS, respectively.

3.4. Comparison of Prognosis between GCLS and Non-GCLSs. Patients with GCLS had a better overall survival than those with non-GCLS (HR 0.500, 95\% CI 0.305-0.821; Table 5). However, there were no significant differences in overall survival rates between GCLS and non-GCLS in EGC. In EBV-associated GC, patients with GCLS had better overall survivals than those with non-GCLS (HR 0.090, 95\% CI 0.025-0.319).

\section{Discussion}

The present study is the first meta-analysis, to the best of our knowledge, to elucidate the clinicopathological characteristics of GCLS. There were four significant findings in this study. First, the estimated prevalence of GCLS was $6.2 \%$ of all GCs. Second, GCLS had a smaller tumor size and higher frequency of the diffuse type of Lauren's classification, occurred in the proximal portion of the stomach, had lymphatic invasion, and had lower pTNM stages compared to non-GCLS. Third, GCLS significantly correlated with EBV positivity in situ hybridization. Fourth, GCLS had a favorable prognosis than non-GCLS.

GCLSs comprise 1-7\% of all GCs [1]. In our eligible studies, the prevalence of GCLS ranged from $1.7 \%$ to $16.5 \%$ $[16,27]$. In a meta-analysis, the estimated rate of GCLS was 0.062 (95\% CI 0.040-0.097). The prevalence rates were
0.054 and 0.136 in EGC and AGC, respectively. However, there was no significant difference in GCLS rates between EGC and AGC ( $P=0.392$ in the metaregression test). As shown in Table 3 , the estimated rates of $\mathrm{pT} 1 / \mathrm{T} 2$ were 0.592 and 0.428 in GCLS and non-GCLS, respectively. In addition, there was no statistical difference in $\mathrm{pT} 1 / \mathrm{T} 2$ rates between GCLS and non-GCLS. According to the WHO classification, GCLS significantly correlated with the proximal stomach/remnant stomach and male sex, as seen in our results [1]. However, because the incidence of GCLS is lower than that of other subtypes, those clinicopathological features can be controversial between studies. In addition, GCLS significantly correlated with a smaller tumor size, diffuse type of Lauren's classification, a lower frequency of lymphatic invasion, and a lower pTNM stage compared to non-GCLS. From our results, the estimated rates of lymphatic and vascular invasions were $25.9 \%$ and $14.6 \%$, respectively. Lim et al. reported that there was no lymphovascular invasion of GCLS in EGC [17]. However, we could not perform the subgroup analysis for lymphovascular invasion based on the $\mathrm{pT}$ stage due to insufficient information. To obtain detailed information, a cumulative study is needed.

Lim et al. reported treatment results of endoscopic resection for the early stage of GCLS (pT1/2) [17]. Histologic differentiation may be important in deciding the treatment modality. However, among 40 GCLSs, only $10 \%$ of cases were diagnosed as GCLS on the pretreatment biopsy. The remaining cases were diagnosed as differentiated adenocarcinomas (60\%) and undifferentiated adenocarcinomas (20\%) [17]. On the pretreatment biopsy, it is difficult to assess whether a poorly differentiated tumor is a GCLS. In our result, GCLS had a low frequency of lymphatic invasion than non-GCLS. In addition, although there was no statistical difference, 
TABLE 1: Main characteristics of the eligible studies.

\begin{tabular}{|c|c|c|c|c|c|c|c|c|c|}
\hline & Location & Patient's group & $\begin{array}{l}\text { Number of } \\
\text { patients }\end{array}$ & $\begin{array}{l}\text { EBV positive } \\
\text { rate* }\end{array}$ & & Location & Patient's group & $\begin{array}{l}\text { Number of } \\
\text { patients }\end{array}$ & $\begin{array}{c}\text { EBV positive } \\
\text { rate* }\end{array}$ \\
\hline \multirow{2}{*}{$\begin{array}{l}\text { Chang } \\
2000\end{array}$} & \multirow[t]{2}{*}{ Korea } & & 30 & \multirow[t]{2}{*}{$66.7 \%$} & $\begin{array}{l}\text { Lopes } \\
2004\end{array}$ & Brazil & GCLS & 7 & $57.1 \%$ \\
\hline & & GCLS w/EBV- & 15 & & Lu 2004 & China & GCLS & 17 & \\
\hline \multirow{2}{*}{$\begin{array}{l}\text { Chang } \\
2001\end{array}$} & \multirow[b]{2}{*}{ Korea } & GCLS & 14 & $50.0 \%$ & & & Non-GCLS & 64 & \\
\hline & & Non-GCLS & 292 & $3.4 \%$ & $\begin{array}{l}\text { Min } \\
2016\end{array}$ & Korea & GCLS & 145 & $85.5 \%$ \\
\hline \multirow{2}{*}{$\begin{array}{l}\text { Cheng } \\
2015\end{array}$} & \multirow{2}{*}{ China } & GCLS w/EBV+ & 8 & & $\begin{array}{c}\text { Mohri } \\
2017\end{array}$ & Japan & GCLS & 15 & $66.7 \%$ \\
\hline & & $\begin{array}{c}\text { Non-GCLS } \\
\text { w/EBV + }\end{array}$ & 45 & & $\begin{array}{l}\text { Ohtani } \\
2009\end{array}$ & Japan & GCLS & 24 & $91.7 \%$ \\
\hline \multirow[b]{2}{*}{ Cho 2003} & \multirow[b]{2}{*}{ Korea } & GCLS & 9 & $77.8 \%$ & & & Non-GCLS & 35 & $5.7 \%$ \\
\hline & & Non-GCLS & 21 & $19.0 \%$ & $\begin{array}{l}\text { Osumi } \\
2019\end{array}$ & Japan & GCLS & 80 & $75.0 \%$ \\
\hline \multirow{2}{*}{ Cho 2004} & \multirow{2}{*}{ Korea } & GCLS & 24 & $79.2 \%$ & $\begin{array}{l}\text { Otsuji } \\
2004\end{array}$ & Japan & GCLS & 31 & \\
\hline & & Non-GCLS & 23 & $8.7 \%$ & & & $\begin{array}{c}\text { Non-GCLS } \\
\text { w/PD }\end{array}$ & 136 & \\
\hline $\begin{array}{l}\text { Gonzalez } \\
2017\end{array}$ & USA & GCLS & 13 & & & & $\begin{array}{c}\text { Non-GCLS } \\
\text { w/WD }\end{array}$ & 799 & \\
\hline Hirai 2016 & Japan & GCLS & 23 & & $\begin{array}{l}\text { Park } \\
2015\end{array}$ & Korea & GCLS & 46 & $80.4 \%$ \\
\hline $\begin{array}{l}\text { Hissong } \\
2018\end{array}$ & USA & GCLS & 31 & $22.6 \%$ & & & Non-GCLS & 4236 & $6.5 \%$ \\
\hline \multirow{4}{*}{$\begin{array}{l}\text { Huang } \\
2013\end{array}$} & \multirow{4}{*}{ Taiwan } & GCLS in EGC & 31 & & $\begin{array}{c}\text { Ramos } \\
2017\end{array}$ & Brazil & GCLS & 7 & \\
\hline & & $\begin{array}{c}\text { Non-GCLS in } \\
\text { EGC }\end{array}$ & 520 & & & & Non-GCLS & 248 & \\
\hline & & GCLS in AGC & 191 & & $\begin{array}{c}\text { Ribeiro } \\
2017\end{array}$ & Portugal & GCLS & 3 & $100.0 \%$ \\
\hline & & $\begin{array}{c}\text { Non-GCLS in } \\
\text { AGC }\end{array}$ & 1217 & & $\begin{array}{c}\text { Selves } \\
1996\end{array}$ & France & GCLS & 6 & $66.7 \%$ \\
\hline \multirow{2}{*}{$\begin{array}{l}\text { Huang } \\
2014\end{array}$} & \multirow{2}{*}{ Taiwan } & GCLS w/EBV+ & 18 & & $\begin{array}{l}\text { Setia } \\
2019\end{array}$ & USA & GCLS & 17 & $64.7 \%$ \\
\hline & & $\begin{array}{c}\text { Non-GCLS } \\
\text { w/EBV + }\end{array}$ & 33 & & $\begin{array}{l}\text { Shin } \\
2017\end{array}$ & Korea & GCLS & 70 & \\
\hline \multirow[b]{2}{*}{ Huh 2016} & \multirow[b]{2}{*}{ Korea } & GCLS & 41 & $72.2 \%$ & & & Non-GCLS & 1626 & \\
\hline & & Non-GCLS & 3344 & & $\begin{array}{l}\text { Song } \\
2010\end{array}$ & USA & GCLS w/EBV+ & 53 & \\
\hline Jing 1997 & Japan & GCLS & 8 & $37.5 \%$ & & & $\begin{array}{c}\text { Non-GCLS } \\
\text { w/EBV + }\end{array}$ & 18 & \\
\hline \multirow[t]{2}{*}{ Kang 2016} & \multirow[t]{2}{*}{ Korea } & GCLS & 60 & & $\begin{array}{l}\text { Tobo } \\
2013\end{array}$ & Japan & GCLS & 104 & $75.0 \%$ \\
\hline & & Non-GCLS & 60 & & & & Non-GCLS & 29 & $0.0 \%$ \\
\hline \multirow[b]{2}{*}{ Lim 2015} & \multirow[b]{2}{*}{ Korea } & GCLS & 274 & $86.1 \%$ & Wu 2000 & Taiwan & GCLS w/EBV+ & 11 & \\
\hline & & Non-GCLS & 822 & & & & $\begin{array}{c}\text { Non-GCLS } \\
\text { w/EBV + }\end{array}$ & 19 & \\
\hline
\end{tabular}


TABLe 1: Continued.

\begin{tabular}{cccccccccc}
\hline & Location & Patient's group & $\begin{array}{c}\text { Number of } \\
\text { patients }\end{array}$ & $\begin{array}{c}\text { EBV positive } \\
\text { rate* }\end{array}$ & Location & Patient's group & $\begin{array}{c}\text { Number of } \\
\text { patients }\end{array}$ & $\begin{array}{c}\text { EBV positive } \\
\text { rate* }\end{array}$ \\
\hline Lim 2017 & Korea & GCLS & 241 & $89.2 \%$ & & & $\begin{array}{c}\text { Non-GCLS } \\
\text { w/EBV- }\end{array}$ & 120 & \\
& Non-GCLS & 1219 & & $\begin{array}{c}\text { Yanagi } \\
2019\end{array}$ & Japan & GCLS & 43 & $60.5 \%$ \\
\hline Lim 2018 & Korea & GCLS & 40 & $90.0 \%$ & $\begin{array}{c}\text { Yuen } \\
1994\end{array}$ & $\begin{array}{c}\text { Hong } \\
\text { Kong }\end{array}$ & GCLS & 7 & $28.6 \%$ \\
\hline
\end{tabular}

*In gastric carcinoma with lymphoid stroma; EBV, Epstein-Barr virus; GCLS, gastric carcinoma with lymphoid stroma; w/, with; EGC, early gastric carcinoma; AGC, advanced gastric carcinoma; PD, poorly differentiated; WD, well differentiated.

TABLE 2: The estimated rates of gastric carcinoma with lymphoid stroma.

\begin{tabular}{lcccccc}
\hline & Number of subsets & $\begin{array}{c}\text { Fixed effect } \\
(95 \% \mathrm{CI})\end{array}$ & $\begin{array}{c}\text { Heterogeneity test } \\
(P \text { value })\end{array}$ & $\begin{array}{c}\text { Random effect } \\
(95 \% \mathrm{CI})\end{array}$ & $\begin{array}{c}\text { Egger's test } \\
(P \text { value })\end{array}$ & $\begin{array}{c}\text { Meta-regression test } \\
(P \text { value })\end{array}$ \\
\hline GCLS rate & 20 & $0.097[0.092,0.103]$ & $<0.001$ & $0.062[0.040,0.097]$ & 0.023 & $0.392 *$ \\
EGC & 5 & $0.087[0.079,0.095]$ & $<0.001$ & $0.054[0.022,0.129]$ & 0.077 & - \\
AGC & 1 & $0.136[0.119,0.155]$ & 1.000 & $0.136[0.119,0.155]$ & - \\
\hline
\end{tabular}

CI, confidence interval; GCLS, gastric carcinoma with lymphoid stroma; EGC, early gastric carcinoma; AGC, advanced gastric carcinoma $*$ EGC vs. AGC.

GCLS showed less-frequent vascular invasion and lymph node metastasis and lower pT1/T2 than non-GCLS. This result suggests that histologic findings of GCLS may not be a contraindication for endoscopic resections, regardless of pathologically confirmed diagnosis. Lim et al. reported that the rate of en bloc resection with endoscopic resection was $97.5 \%$ in GCLS at early stages [17]. In other reports, the complete resection rate was $60-80 \%$ in undifferentiated EGCs [39-41]. The histologic characteristics of GCLS, which is embedded by peritumoral lymphocytes, may be affected by this higher complete resection rate. In the pretreatment diagnosis, it is necessary to consider a GCLS when differentiating from poorly/undifferentiated adenocarcinoma.

Medullary carcinoma is also described in colorectal and breast cancers. The characteristic histologic finding of these carcinomas is poorly differentiated tumor cells with peritumoral lymphocytic infiltration. However, diagnostic criteria are slightly different between tumors. In breast cancer, medullary carcinoma is defined as (1) sheets of cells with indistinct cell borders (syncytial growth) in greater than $75 \%$ of the tumor, (2) sharply circumscribed and pushing borders, and (3) moderate to poor differentiation [42]. In colorectal cancers, the malignant, well-circumscribed neoplasm has a solid growth pattern (no gland formation) and pushing border. We previously reported the clinicopathologic characteristics and prognosis of colorectal medullary carcinomas through a meta-analysis [43]. In colorectal cancers, patients with medullary carcinoma had a significantly better overall survival rate compared to patients with poorly differentiated and undifferentiated adenocarcinoma [43]. In the present study, GCLS had a better prognosis than non-GCLS. However, in the subgroup analysis on tumor depth (EGC vs. AGC), a different result was obtained. There was no significant difference in survival rate between GCLS and non-GCLS in EGCs. However, in AGCs, the prognosis was better in GCLS than that in non-GCLS. The estimated rate of pT1/T2 was $59.2 \%$ in all GCLSs. This result confirmed that the better prognosis of GCLS was not caused by a lower pT1/T2 rate compared to non-GCLS. In colorectal cancer, medullary carcinoma had a better prognosis than poorly differentiated and undifferentiated adenocarcinoma. As described above, GCLS significantly correlated with EBV positivity. We checked the difference in survival between EBV positivity and negativity in GCLS. However, there was no significant difference in prognosis between the two groups.

The characteristic finding of GCLS is peritumoral and tumor-infiltrating lymphocytes. In addition, cell nests of GCLS can be embedded in prominent lymphocytic infiltrates. Because studies against the immunotherapeutic effects of various cancers are recently increasing, the correlation between TILs and PD-L1 expression is useful to understand the treatment in GCLS. Because EBV positivity of GCLS was high, molecular characteristics of GCLS and EBVaGC may be overlapping. PD-L1 gene amplification was elevated in EBV-associated GCs [44]. In the previous meta-analysis, the PD-L1 expression rate of tumor cells was $47.0 \%$ in GCs [45]. In the present study, tumor cells of GCLS were found in $67.7 \%$ of GCLSs. The PD-L1 expression rates were higher in GCLSs than that in overall cases. Immune cells showed PD-L1 expression in $74.2 \%$ of GCLS. Although PD-L1 expressions between GCLS and non-GCLS could not be compared, high PD-L1 expression of GCLS is meaningful. Because the implication of tumor-infiltrating lymphocytes is not clear in GC, further evaluation in GCLS will be needed.

In GCLS, EBV positivity varied from $22.6 \%$ to $100 \%$ by reports $[9,27]$. We found higher EBV positivity in GCLS than in non-GCLS $(72.3 \%$ vs. $6.4 \% ; P<0.001$ in the metaregression test). The positive rates of EBV in non-GCLS varied from $0 \%$ to $19 \%$ among eligible studies $[5,32]$. However, because the EBV positive rate was not $100 \%$, the comparison of clinicopathological characteristics between EBV positive (EBVaGCLS) and negative GCLSs (non-EBVaGCLS) can be 
TABLE 3: Clinicopathological significances of gastric carcinoma with lymphoid stroma.

\begin{tabular}{|c|c|c|c|c|c|c|}
\hline & $\begin{array}{l}\text { Number of } \\
\text { subsets }\end{array}$ & $\begin{array}{l}\text { Fixed effect } \\
(95 \% \mathrm{CI})\end{array}$ & $\begin{array}{l}\text { Heterogeneity test } \\
\text { ( } P \text { value })\end{array}$ & $\begin{array}{c}\text { Random effect } \\
(95 \% \mathrm{CI})\end{array}$ & $\begin{array}{l}\text { Egger's test } \\
(P \text { value })\end{array}$ & $\begin{array}{c}\text { Meta-regression test } \\
(P \text { value })\end{array}$ \\
\hline \multicolumn{7}{|l|}{ Age } \\
\hline GCLS & 13 & $57.892[57.293,58.491]$ & $<0.001$ & $58.182[56.857,59.507]$ & 0.412 & \multirow[b]{2}{*}{0.152} \\
\hline $\begin{array}{l}\text { Non- } \\
\text { GCLS }\end{array}$ & 11 & $58.252[58.059,58.445]$ & $<0.001$ & $59.864[58.410,61.318]$ & 0.164 & \\
\hline \multicolumn{7}{|c|}{ Male ratio } \\
\hline GCLS & 26 & $0.794[0.772,0.815]$ & $<0.001$ & $0.765[0.712,0.811]$ & 0.064 & \multirow[b]{2}{*}{0.052} \\
\hline $\begin{array}{l}\text { Non- } \\
\text { GCLS }\end{array}$ & 18 & $0.686[0.678,0.694]$ & $<0.001$ & $0.709[0.665,0.751]$ & 0.333 & \\
\hline \multicolumn{7}{|l|}{ Size $(\mathrm{cm})$} \\
\hline GCLS & 7 & $2.763[2.618,2.908]$ & $<0.001$ & $3.275[2.521,4.029]$ & 0.181 & \multirow[b]{2}{*}{0.032} \\
\hline $\begin{array}{l}\text { Non- } \\
\text { GCLS }\end{array}$ & 7 & $2.908[2.865,2.951]$ & $<0.001$ & $4.636[3.786,5.486]$ & 0.018 & \\
\hline \multicolumn{7}{|c|}{ Lauren's classification, diffuse type } \\
\hline GCLS & 10 & $0.554[0.504,0.602]$ & $<0.001$ & $0.577[0.437,0.705]$ & 0.512 & \multirow[b]{2}{*}{0.036} \\
\hline $\begin{array}{l}\text { Non- } \\
\text { GCLS }\end{array}$ & 8 & $0.444[0.433,0.455]$ & $<0.001$ & $0.455[0.397,0.514]$ & 0.949 & \\
\hline \multicolumn{7}{|c|}{ Tumor differentiation, poorly } \\
\hline GCLS & 8 & $0.407[0.369,0.446]$ & $<0.001$ & $0.710[0.474,0.870]$ & 0.070 & \multirow[b]{2}{*}{0.376} \\
\hline $\begin{array}{r}\text { Non- } \\
\text { GCLS6 } \\
\end{array}$ & 6 & $0.618[0.605,0.630]$ & 0.009 & $0.610[0.574,0.645]$ & 0.859 & \\
\hline \multicolumn{7}{|c|}{ Tumor location, proximal $1 / 3$} \\
\hline GCLS & 15 & $0.280[0.254,0.308]$ & $<0.001$ & $0.249[0.190,0.319]$ & 0.223 & \multirow[b]{2}{*}{$<0.001$} \\
\hline $\begin{array}{l}\text { Non- } \\
\text { GCLS }\end{array}$ & 14 & $0.132[0.126,0.137]$ & $<0.001$ & $0.148[0.123,0.177]$ & 0.375 & \\
\hline \multicolumn{7}{|c|}{ Lymphatic invasion } \\
\hline GCLS & 6 & $0.330[0.253,0.417]$ & $<0.001$ & $0.259[0.113,0.490]$ & 0.369 & \multirow[b]{2}{*}{0.024} \\
\hline $\begin{array}{l}\text { Non- } \\
\text { GCLS }\end{array}$ & 7 & $0.381[0.368,0.395]$ & $<0.001$ & $0.516[0.405,0.625]$ & 0.116 & \\
\hline \multicolumn{7}{|c|}{ Vascular invasion } \\
\hline GCLS & 7 & $0.257[0.193,0.334]$ & $<0.001$ & $0.146[0.049,0.361]$ & 0.336 & \multirow[b]{2}{*}{0.666} \\
\hline $\begin{array}{l}\text { Non- } \\
\text { GCLS }\end{array}$ & 8 & $0.127[0.117,0.137]$ & $<0.001$ & $0.214[0.120,0.353]$ & 0.099 & \\
\hline \multicolumn{7}{|c|}{ Perineural invasion } \\
\hline GCLS & 13 & $0.150[0.122,0.183]$ & $<0.001$ & $0.104[0.056,0.184]$ & 0.170 & \multirow[b]{2}{*}{0.335} \\
\hline $\begin{array}{l}\text { Non- } \\
\text { GCLS }\end{array}$ & 9 & $0.129[0.122,0.137]$ & $<0.001$ & $0.158[0.081,0.284]$ & 0.977 & \\
\hline \multicolumn{7}{|c|}{ pT stage, pT1/T2 } \\
\hline GCLS & 14 & $0.624[0.587,0.660]$ & $<0.001$ & $0.592[0.472,0.702]$ & 0.559 & \multirow[b]{2}{*}{0.102} \\
\hline $\begin{array}{l}\text { Non- } \\
\text { GCLS } \\
\end{array}$ & 12 & $0.728[0.716,0.740]$ & $<0.001$ & $0.428[0.301,0.565]$ & 0.005 & \\
\hline \multicolumn{7}{|c|}{ Lymph node metastasis } \\
\hline GCLS & 20 & $0.351[0.322,0.381]$ & $<0.001$ & $0.308[0.217,0.417]$ & 0.368 & \multirow[b]{2}{*}{0.100} \\
\hline $\begin{array}{l}\text { Non- } \\
\text { GCLS }\end{array}$ & 15 & $0.324[0.314,0.333]$ & $<0.001$ & $0.462[0.322,0.608]$ & 0.486 & \\
\hline \multicolumn{7}{|c|}{ Distant metastasis } \\
\hline GCLS & 2 & $0.197[0.057,0.499]$ & $<0.001$ & $0.197[0.057,0.499]$ & - & - \\
\hline
\end{tabular}


TABLe 3: Continued.

\begin{tabular}{lcccccc}
\hline & $\begin{array}{c}\text { Number of } \\
\text { subsets }\end{array}$ & $\begin{array}{c}\text { Fixed effect } \\
(95 \% \mathrm{CI})\end{array}$ & $\begin{array}{c}\text { Heterogeneity test } \\
(P \text { value })\end{array}$ & $\begin{array}{c}\text { Random effect } \\
(95 \% \mathrm{CI})\end{array}$ & $\begin{array}{c}\text { Egger's test } \\
(P \text { value })\end{array}$ & $\begin{array}{c}\text { Meta-regression test } \\
(P \text { value })\end{array}$ \\
\hline $\begin{array}{l}\text { pTNM stage, I/II } \\
\text { GCLS }\end{array}$ & 13 & $0.696[0.659,0.731]$ & $<0.001$ & $0.750[0.599,0.858]$ & 0.428 & 0.042 \\
$\begin{array}{l}\text { Non- } \\
\text { GCLS }\end{array}$ & 11 & $0.685[0.673,0.697]$ & $<0.001$ & $0.500[0.317,0.683]$ & 0.240 \\
\hline
\end{tabular}

CI, confidence interval; GCLS, gastric carcinoma with lymphoid stroma.

TABLE 4: The estimated rates of various markers in gastric carcinoma with lymphoid stroma.

\begin{tabular}{|c|c|c|c|c|c|c|}
\hline & Number of subsets & $\begin{array}{c}\text { Fixed effect } \\
(95 \% \mathrm{CI})\end{array}$ & $\begin{array}{l}\text { Heterogeneity test } \\
(P \text { value })\end{array}$ & $\begin{array}{c}\text { Random effect } \\
(95 \% \mathrm{CI})\end{array}$ & $\begin{array}{c}\text { Egger's test } \\
(P \text { value })\end{array}$ & $\begin{array}{c}\text { Meta-regression test } \\
(P \text { value })\end{array}$ \\
\hline \multicolumn{7}{|l|}{ EBV positivity } \\
\hline GCLS & 22 & $0.780[0.754,0.805]$ & $<0.001$ & $0.723[0.643,0.791]$ & 0.029 & \multirow{2}{*}{$<0.001$} \\
\hline Non-GCLS & 6 & $0.063[0.052,0.076]$ & 0.067 & $0.064[0.039,0.103]$ & 0.970 & \\
\hline \multicolumn{7}{|c|}{ Microsatellite instable } \\
\hline GCLS & 1 & $0.059[0.008,0.320]$ & 1.000 & $0.059[0.008,0.320]$ & - & - \\
\hline \multicolumn{7}{|c|}{ PD-L1 in tumor cells } \\
\hline GCLS & 1 & $0.677[0.497,0.817]$ & 1.000 & $0.677[0.497,0.817]$ & - & - \\
\hline \multicolumn{7}{|c|}{ PD-L1 in immune cells } \\
\hline GCLS & 1 & $0.742[0.563,0.865]$ & 1.000 & $0.742[0.563,0.865]$ & - & - \\
\hline \multicolumn{7}{|l|}{ HER2 } \\
\hline GCLS & 3 & $0.026[0.005,0.120]$ & 0.883 & $0.026[0.005,0.120]$ & 0.089 & \multirow{2}{*}{$<0.001$} \\
\hline Non-GCLS & 1 & $0.632[0.403,0.813]$ & 1.000 & $0.632[0.403,0.813]$ & - & \\
\hline \multicolumn{7}{|l|}{ p53 } \\
\hline GCLS & 5 & $0.368[0.253,0.499]$ & $<0.001$ & $0.386[0.140,0.707]$ & 0.854 & \multirow{2}{*}{0.554} \\
\hline Non-GCLS & 2 & $0.494[0.388,0.600]$ & 0.401 & $0.494[0.388,0.600]$ & - & \\
\hline
\end{tabular}

CI, confidence interval; EBV, Epstein-Barr virus.

TABle 5: The prognostic implications of gastric carcinoma with lymphoid stroma.

\begin{tabular}{|c|c|c|c|c|c|}
\hline & Number of subsets & $\begin{array}{l}\text { Fixed effect } \\
(95 \% \mathrm{CI})\end{array}$ & $\begin{array}{l}\text { Heterogeneity test } \\
\text { ( } P \text { value })\end{array}$ & $\begin{array}{l}\text { Random effect } \\
\text { (95\% CI) }\end{array}$ & $\begin{array}{l}\text { Egger's test } \\
(P \text { value })\end{array}$ \\
\hline \multicolumn{6}{|l|}{ GCLS vs. non-GCLS } \\
\hline Overall & 6 & $0.854[0.767,0.951]$ & $<0.001$ & $0.500[0.305,0.821]$ & 0.023 \\
\hline EGC & 1 & $1.022[0.788,1.325]$ & 1.000 & $1.022[0.788,1.325]$ & - \\
\hline AGC & 1 & $0.863[0.765,0.972]$ & 1.000 & $0.863[0.765,0.972]$ & - \\
\hline EBVaGC & 2 & $0.090[0.025,0.319]$ & 0.884 & $0.090[0.025,0.319]$ & - \\
\hline $\mathrm{EBV}+$ vs. EBV- in GCLS & 2 & $0.573[0.305,1.076]$ & 0.147 & $0.477[0.160,1.425]$ & - \\
\hline
\end{tabular}

CI, confidence interval; GCLS, gastric carcinoma with lymphoid stroma; EGC, early gastric carcinoma; AGC, advanced gastric carcinoma; EBV, Epstein-Barr virus.

useful in understanding GCLS. Chang et al. reported that EBVaGCLS significantly correlated with the male sex, the middle third of the stomach, and the diffuse type of Lauren's classification compared to non-EBVaGCLS [2]. Min et al. reported that non-EBVaGCLS correlated with older age, female, advanced $\mathrm{T}$ stage, and advanced pTNM [20]. Previous studies have reported that EBV positivity significantly correlated with sex and tumor location [21,25,52]. Also, GCLS significantly correlated with male patients and proximal tumor location. These characteristics of GCLS overlapped with EBVaGC. The cause may be a high EBV positive rate of GCLS. In addition, GCLS significantly correlated with less-frequent lymphatic invasion and lower pTNM stage. Min et al. reported that EBV positive cases showed a better overall survival rate than EBV negative cases in GCLS [20]. However, there was no significant difference in survival rate between EBVaGCLS 
and non-EBVaGCLS in our study. We additionally evaluated survival rates between GCLS and non-GCLS in EBVaGCs. Patients with GCLS showed a favorable prognosis than those with non-GCLS in EBVaGCs (HR 0.090, 95\% CI 0.025-0.319).

This study has some limitations. First, the analysis of MSI status in GCLS could not be performed due to insufficient information. Setia et al. reported that one case out of 17 GCLS showed a microsatellite instable (MSI) status [29]. Second, PD-L1 expression rates were only shown in GCLS, but not in non-GCLS. In included studies, there was no information for PD-L1 expression of non-GCLS. In conclusion, GCLS was found in $6.2 \%$ of overall GC. In addition, GCLS was significantly correlated with male patients and the proximal tumor location of the stomach. Because GCLS was associated with a better prognosis, the histologic finding can be useful for predicting the patient's prognosis.

\section{Data Availability}

The data supporting this meta-analysis are from previously reported studies and datasets, which have been cited. There was the processed data from the corresponding author upon request.

\section{Ethical Approval}

All procedures performed in studies involving human participants were in accordance with the ethical standards of the institutional research committee and with the 1964 Helsinki declaration and its later amendments or comparable ethical standards.

\section{Conflicts of Interest}

The authors declare that they have no potential conflicts of interest.

\section{Authors' Contributions}

Jung-Soo Pyo and Nae Yu Kim equally contributed to this work.

\section{Acknowledgments}

This study was supported by Daewon Pharmaceutical in 2020.

\section{References}

[1] WHO Classification of Tumours Editorial Board, WHO Classification of Tumours of the Digestive System, International Agency for Research on Cancer, Lyon, France, 5th ed. edition, 2018.

[2] M. S. Chang, W. H. Kim, C. W. Kim, and Y. I. Kim, "EpsteinBarr virus in gastric carcinomas with lymphoid stroma," Histopathology, vol. 37, no. 4, pp. 309-315, 2000.

[3] M. S. Chang, H. S. Lee, C. W. Kim, Y. I. Kim, and W. H. Kim, "Clinicopathologic characteristics of Epstein-Barr virusincorporated gastric cancers in Korea," Pathology, Research and Practice, vol. 197, no. 6, pp. 395-400, 2001.
[4] N. Cheng, D. Y. Hui, Y. Liu et al., "Is gastric lymphoepithelioma-like carcinoma a special subtype of EBVassociated gastric carcinoma? New insight based on clinicopathological features and EBV genome polymorphisms," Gastric Cancer, vol. 18, no. 2, pp. 246-255, 2015.

[5] H. J. Cho, J. Y. Kim, J. Yoo, and S. S. Lee, "Gastric carcinoma with lymphoid stroma: incidence of EBV and Helicobacter pylori infection," Applied Immunohistochemistry \& Molecular Morphology, vol. 11, no. 2, pp. 149-152, 2003.

[6] M. Y. Cho, T. H. Kim, S. Y. Yi, W. H. Jung, and K. H. Park, "Relationship between Epstein-Barr virus-encoded RNA expression, apoptosis and lymphocytic infiltration in gastric carcinoma with lymphoid-rich stroma," Medical Principles and Practice, vol. 13, no. 6, pp. 353-360, 2004.

[7] R. S. Gonzalez, J. M. M. Cates, F. Revetta, L. A. McMahon, and K. Washington, "Gastric carcinomas with lymphoid stroma," American Journal of Clinical Pathology, vol. 148, no. 6, pp. 477-484, 2017.

[8] H. Hirai, T. Yoshizawa, S. Morohashi et al., "Clinicopathological significance of gastric poorly differentiated medullary carcinoma," Biomedical Research, vol. 37, no. 2, pp. 77-84, 2016.

[9] E. Hissong, G. Ramrattan, P. Zhang et al., "Gastric carcinomas with lymphoid stroma: an evaluation of the histopathologic and molecular features," The American Journal of Surgical Pathology, vol. 42, no. 4, pp. 453-462, 2018.

[10] K. H. Huang, R. F. Wang, M. H. Yang et al., "Advanced gastric cancer patients with lymphoid stroma have better survival than those without," Journal of Surgical Oncology, vol. 107, no. 5, pp. 523-528, 2013.

[11] S.-C. Huang, K.-F. Ng, K.-H. Chen et al., "Prognostic factors in Epstein-Barr virus-associated stage I-III gastric carcinoma: implications for a unique type of carcinogenesis," Oncology Reports, vol. 32, no. 2, pp. 530-538, 2014.

[12] C. W. Huh, D. H. Jung, H. Kim et al., "Clinicopathologic features of gastric carcinoma with lymphoid stroma in early gastric cancer," Journal of Surgical Oncology, vol. 114, no. 6, pp. 769-772, 2016.

[13] X. Jing, Y. Nakamura, M. Nakamura et al., "Detection of Epstein-Barr virus DNA in gastric carcinoma with lymphoid stroma," Viral Immunology, vol. 10, no. 1, pp. 49-58, 1997.

[14] B. W. Kang, A. N. Seo, S. Yoon et al., "Prognostic value of tumor-infiltrating lymphocytes in Epstein-Barr virusassociated gastric cancer," Annals of Oncology, vol. 27, no. 3, pp. 494-501, 2016.

[15] H. Lim, Y. S. Park, J. H. Lee et al., "Features of gastric carcinoma with lymphoid stroma associated with Epstein-Barr virus," Clinical Gastroenterology and Hepatology, vol. 13, no. 10, pp. 1738-1744.e2, 2015.

[16] H. Lim, I. S. Lee, J. H. Lee et al., "Clinical application of early gastric carcinoma with lymphoid stroma based on lymph node metastasis status," Gastric Cancer, vol. 20, no. 5, pp. 793-801, 2017.

[17] H. Lim, J. H. Lee, Y. S. Park et al., “A single-center experience of endoscopic resection for early gastric cancer with lymphoid stroma," Journal of Gastric Cancer, vol. 18, no. 4, pp. 400-408, 2018.

[18] L. F. Lopes, M. M. Bacchi, D. Elgui-de-Oliveira, S. G. Zanati, M. Alvarenga, and C. E. Bacchi, "Epstein-Barr virus infection and gastric carcinoma in São Paulo State, Brazil," Brazilian Journal of Medical and Biological Research, vol. 37, no. 11, pp. 1707-1712, 2004. 
[19] B.-J. Lu, M. Lai, L. Cheng, J.-Y. Xu, and Q. Huang, "Gastric medullary carcinoma, a distinct entity associated with microsatellite instability- $\mathrm{H}$, prominent intraepithelial lymphocytes and improved prognosis," Histopathology, vol. 45, no. 5, pp. 485-492, 2004.

[20] B. H. Min, C. H. Tae, S. M. Ahn et al., "Epstein-Barr virus infection serves as an independent predictor of survival in patients with lymphoepithelioma-like gastric carcinoma," Gastric Cancer, vol. 19, no. 3, pp. 852-859, 2016.

[21] T. Mohri, K. Nagata, S. Kuwamoto et al., “Aberrant expression of AID and AID activators of NF- $\kappa$ B and PAX5 is irrelevant to EBV-associated gastric cancers, but is associated with carcinogenesis in certain EBV-non-associated gastric cancers," Oncology Letters, vol. 13, no. 6, pp. 4133-4140, 2017.

[22] H. Ohtani, Z. Jin, S. Takegawa, T. Nakayama, and O. Yoshie, "Abundant expression of CXCL9 (MIG) by stromal cells that include dendritic cells and accumulation of CXCR3+ T cells in lymphocyte-rich gastric carcinoma," The Journal of Pathology, vol. 217, no. 1, pp. 21-31, 2009.

[23] H. Osumi, H. Kawachi, T. Yoshio et al., "Epstein-Barr virus status is a promising biomarker for endoscopic resection in early gastric cancer: proposal of a novel therapeutic strategy," Journal of Gastroenterology, vol. 54, no. 9, pp. 774-783, 2019.

[24] E. Otsuji, Y. Kuriu, D. Ichikawa et al., "Clinicopathologic and prognostic characterization of poorly differentiated medullary-type gastric adenocarcinoma," World Journal of Surgery, vol. 28, no. 9, pp. 862-865, 2004.

[25] S. Park, M. G. Choi, K. M. Kim et al., "Lymphoepitheliomalike carcinoma: a distinct type of gastric cancer," The Journal of Surgical Research, vol. 194, no. 2, pp. 458-463, 2015.

[26] M. F. K. P. Ramos, M. A. Pereira, A. R. Dias et al., "Lymphoepithelioma-like gastric carcinoma: clinicopathological characteristics and infection status," The Journal of Surgical Research, vol. 210, pp. 159-168, 2017.

[27] J. Ribeiro, A. Oliveira, M. Malta et al., "Clinical and pathological characterization of Epstein-Barr virus-associated gastric carcinomas in Portugal," World Journal of Gastroenterology, vol. 23, no. 40, pp. 7292-7302, 2017.

[28] J. Selves, F. Bibeau, P. Brousset et al., "Epstein-Barr virus latent and replicative gene expression in gastric carcinoma," Histopathology, vol. 28, no. 2, pp. 121-127, 2003.

[29] N. Setia, S. Ahn, H. S. Han, D. Y. Park, and G. Y. Lauwers, "Predictive value of WHO classification for PD-L1 and Her2/$\mathrm{Neu}$ expression and distinct associations with protein expression based classification in gastric carcinoma," Human Pathology, vol. 94, pp. 64-70, 2019.

[30] D. H. Shin, G. H. Kim, B. E. Lee et al., "Clinicopathologic features of early gastric carcinoma with lymphoid stroma and feasibility of endoscopic submucosal dissection," Surgical Endoscopy, vol. 31, no. 10, pp. 4156-4164, 2017.

[31] H. J. Song, A. Srivastava, J. Lee et al., "Host inflammatory response predicts survival of patients with Epstein-Barr virus-associated gastric carcinoma," Gastroenterology, vol. 139, no. 1, pp. 84-92.e2, 2010.

[32] T. Tobo, M. Hirahashi, T. Yao, S. Aishima, and Y. Oda, "Ezrin expression and its phosphorylation in gastric carcinoma with lymphoid stroma and Epstein-Barr virus infection," Molecular and Clinical Oncology, vol. 1, no. 2, pp. 220-224, 2013.

[33] M. S. Wu, C. T. Shun, C. C. Wu et al., "Epstein-Barr virusassociated gastric carcinomas: relation to $\mathrm{H}$. pylori infection and genetic alterations," Gastroenterology, vol. 118, no. 6, pp. 1031-1038, 2000.

[34] A. Yanagi, J. Nishikawa, K. Shimokuri et al., "Clinicopathologic characteristics of Epstein-Barr virus-associated gastric cancer over the past decade in Japan," Microorganisms, vol. 7, no. 9, p. 305, 2019.

[35] S. T. Yuen, L. P. Chung, S. Y. Leung, I. S. C. Luk, S. Y. Chan, and J. Ho, "In situ detection of Epstein-Barr virus in gastric and colorectal adenocarcinomas," The American Journal of Surgical Pathology, vol. 18, no. 11, pp. 1158-1163, 1994.

[36] R. Chetty, "Gastrointestinal cancers accompanied by a dense lymphoid component: an overview with special reference to gastric and colonic medullary and lymphoepithelioma-like carcinomas," Journal of Clinical Pathology, vol. 65, no. 12, pp. 1062-1065, 2012.

[37] M. K. Parmar, V. Torri, and L. Stewart, "Extracting summary statistics to perform meta-analyses of the published literature for survival endpoints," Statistics in Medicine, vol. 17, no. 24, pp. 2815-2834, 1998.

[38] S. Yusuf, R. Peto, J. Lewis, R. Collins, and P. Sleight, "Beta blockade during and after myocardial infarction: an overview of the randomized trials," Progress in Cardiovascular Diseases, vol. 27, no. 5, pp. 335-371, 1985.

[39] J. Y. Ahn, H. J. Park, Y. S. Park et al., "Endoscopic resection for undifferentiated-type early gastric cancer: immediate endoscopic outcomes and long-term survivals," Digestive Diseases and Sciences, vol. 61, no. 4, pp. 1158-1164, 2016.

[40] C. S. Bang, G. H. Baik, I. S. Shin et al., "Endoscopic submucosal dissection for early gastric cancer with undifferentiated-type histology: a meta-analysis," World Journal of Gastroenterology, vol. 21, no. 19, pp. 6032-6043, 2015.

[41] H. Y. Kang, S. G. Kim, J. S. Kim, H. C. Jung, and I. S. Song, "Clinical outcomes of endoscopic submucosal dissection for undifferentiated early gastric cancer," Surgical Endoscopy, vol. 24, no. 3, pp. 509-516, 2010.

[42] WHO Classification of Tumours Editorial Board, WHO classification of tumours of the breast, International Agency for Research on Cancer, Lyon, France, 5th edition, 2018.

[43] J. S. Pyo, J. H. Sohn, and G. Kang, "Medullary carcinoma in the colorectum: a systematic review and meta-analysis," Human Pathology, vol. 53, pp. 91-96, 2016.

[44] Cancer Genome Atlas Research Network, "Comprehensive molecular characterization of gastric adenocarcinoma," Nature, vol. 513, no. 7517, pp. 202-209, 2014.

[45] J. S. Pyo, G. Kang, and J. Y. Kim, "Prognostic role of PD-L1 in malignant solid tumors: a meta-analysis," The International Journal of Biological Markers, vol. 32, no. 1, pp. e68-e74, 2017. 